\title{
National plan for detection and treatment of retinopathy of prematurity
}

\section{Plan nacional de detección y tratamiento de la retinopatía del premature}

\author{
Luis P. Orozco-Gómez $z^{1,2,3 *}$
}

${ }^{1}$ President of the Pan American Society of Retinopathy of Prematurity; ${ }^{2} R O P$ Mexico group; ${ }^{3}$ Ophthalmology Service, Centro Médico Nacional 20 de Noviembre. Mexico City, Mexico

\begin{abstract}
We present a historical summary of the work performed by the Sociedad Mexicana de Oftalmología, the ROP Mexico Group and the Ministry of Health for the development of the national plan for detection and treatment of premature retinopathy.

Key words: National plan ROP Mexico. Prematurity. Retinopathy. Blindness.
\end{abstract}

\section{Resumen}

Se presenta el resumen histórico del trabajo realizado por la Sociedad Mexicana de Oftalmología, el Grupo ROP México y la Secretaría de Salud para el desarrollo del plan nacional de detección y tratamiento de la retinopatía del prematuro.

Palabras clave: Plan Nacional ROP México. Prematuro. Retinopatía. Ceguera.

\section{Correspondence:}

*Luis P. Orozco-Gómez

San Francisco, 1626 - 605

Col. Del Valle

C.P. 03100, Mexico City, Mexico

E-mail: Iporozco@ issste.gob.mx
Available online: 01-11-2019

Date of reception: 09-12-2018 Date of acceptance: 18-07-2019 DOI: 10.24875/RMOE.M19000089
Rev Mex Oftalmol (Eng). 2019;93(6):286-293

www.rmo.com.mx 2604-1731/@ 2019 Sociedad Mexicana de Oftalmología. Published by Permanyer México SA de CV. This is an open access article under the CC BY-NC-ND license (http://creativecommons.org/licenses/by-nc-nd/4.0/). 
To put into the context what retinopathy of prematurity (ROP) means, we have to understand that it is a disorder that only occurs in those children born from a pregnancy that is interrupted before completing the normal growth and development expected after a 40-week pregnancy.

The causes for a baby to be born prematurely are diverse, and they are related to maternal diseases or with alterations that affect the baby. All these premature newborns must be admitted to intensive care units, where the intervention of neonatologists and nurses is crucial for them to develop and survive. Once this critical period has elapsed, around the fourth week of life, the fundus should be assessed to determine the vascular state of the retina and make therapeutic decisions to avoid blindness.

In the mid-1980s, some ROP detection programs were initiated, mainly in cities such as Guadalajara, Mexico City and Monterrey. In order to avoid blindness in these patients, some centers began their programs and accumulated cases and experience in their management. From 2000 the efforts were doubled based on the Vision 20/20 Program of the World Health Organization (WHO) whose general objective was to achieve a reduction of $50 \%$ in preventable cases of blindness by 2020 .

In 2001, Dr. Federico Graue, as president of the Sociedad Mexicana de Oftalmología, summoned all physicians from general and ophthalmological hospitals that were related to the attention of premature newborns to the meeting organized by the International Council of Ophthalmology, to share the reality of the diagnosis and treatment of ROP in our country. For that meeting, Dr. Clare E. Gilbert of the Eye Health International Center, Dr. Andrea Zin, of the Oswaldo Cruz Foundation, Rio de Janeiro (FIOCRUZ), and Dr. Luz Gordillo Robles, of the Damos Institute in Lima, Peru, were invited to help dimension the Mexican situation, since there was no information in the literature regarding this issue, and only the world bank had an estimate of the number of blind patients per year in Mexico due to this disease.

At that meeting, only three hospitals had a formal ROP screening plan. The Centro Médico Nacional (CMN) 20 de Noviembre of the Instituto de Seguridad y Servicios Sociales de los Trabajadores del Estado (ISSSTE), the Hospital de Pediatría del Centro Médico Nacional Siglo XXI of the Instituto Mexicano del Seguro Social (IMSS) and the Hospital Civil de Guadalajara

Since that year when the first national working meeting on ROP was held with the support and intervention of various public, social and private groups, such as the Sociedad Mexicana de Oftalmología, the Mexican Retina Association, various ONG, such as CBM (Christoffel Blinden Mission) and the National Network for the Prevention of Disability, among others, as well as the pharmaceutical industry, such as Grin Laboratories, Allergan Laboratories, etc., the Ministry of Health through the National Center for Gender Equity and Reproductive Health, the Ibero-American Society of Neonatology and the International Agency for the Prevention of Blindness, pediatric medical associations, such as the Mexican Association of Pediatrics, the National Federation of Neonatology of Mexico, and nursing associations, such as the Mexican Association of Neonatal Nurses, it has been achieved that there are more programs for the detection and treatment of ROP in our country and, although this increase has been very important, there is still much to do.

On March 4, 2004, it was published in the Official Gazette of the Federation, the creation of the National Council for the Prevention and treatment of Visual Diseases as the advisory body and permanent instance for the coordination and agreement of the actions of the public, social and private sectors regarding research, prevention, diagnosis and comprehensive treatment of the visual diseases detected in the Mexican population.

In 2005, the ROP Mexico Group was formed with the valuable intervention of different specialists, mainly general ophthalmologists, pediatric ophthalmologists, retinologists, pediatricians, neonatologists and neonatal nurses, among others, and with the support of the pharmaceutical industry, ONGs and government organizations. Different dissemination presentations were carried out on the subject in different scenarios, such as state hospitals with neonatal units, medical congresses of pediatrics, ophthalmology, neonatology and nursing, both nationally and internationally. In 5 years, more than 50 presentations were carried out, trying to integrate ROP in the curricula of general medicine and of the different medical specialties involved in the management of ROP, as well as to include the parents of premature children in the spread of knowledge about this condition. Brochures and informative posters on the subject were also distributed in obstetric hospitals and neonatal units.

In 2005, a group of ophthalmologists, neonatologists and nurses participated in the creation of the "Guidelines for the examination, detection and treatment of retinopathy of prematurity in Latin American countries", distributed in Latin America and in our country. It was 
the first instrument of mass medical dissemination concerning ROP.

The ROP Mexico Group received the task of holding annual meetings to gather information about ROP in Mexico, and this has made possible to have a small sample on the subject and understand its importance and relevance as a public health problem in our country. In 2007, the ROP Mexico Group conducted a survey in schools for the visually impaired and blind in three states of the country to identify the primary cause of this disability. In Michoacan, it was observed that in the two schools for the blind of this state, ROP contributed in 40 and $60 \%$ as a cause of blindness. In the state of Morelos, in one center it was found that ROP and tapeto-retinal dystrophies were the most frequent causes of blindness, each responsible for $14 \%$ of the population with blindness. In Mexico City, at the Center for the Rehabilitation of the Blind and Visually Impaired at the Instituto de Oftalmología, it was found that $30 \%$ of blindness cases in children under 18 years of age were due to prematurity.

Due to the affiliation of our country through the Federal Ministry of Health to the WHO Vision 20/20 Program, in 2005, the National Center for Gender Equity and Reproductive Health of the Ministry of Health itself held working meetings with about 100 participants -ophthalmologists, retinologists, pediatricians, neonatologists and neonatal nurses that represented the vast majority of the states of our country. In October 2007, the "Technical Guidelines for the Management of Retinopathy of Prematurity" (ISBN 978-970-721-441-5) were published and distributed through the Ministry of Health to all hospitals of the country within the health system, indicating the need to initiate programs for the detection and treatment of ROP in hospitals that attend premature newborns. This technical guidelines had a second reprint in October 2008. Although these technical guidelines issued by the Federal Ministry of Health are not mandatory, they are recommendations made to the entire national health system (Ministry of Health (SSA), Instituto Mexicano del Seguro Social (Mexican Social Security Institute, IMSS), Instituto de Seguridad y Servicios Sociales de los Trabajadores del Estado (Institute of Social Security and Services of State Workers, ISSTE), Petróleos Mexicanos (PM), Secretaría de la Defensa Nacional (Secretariat of National Defense SEDENA), etc.), and it was a breakthrough because there are few diseases in which, due to their importance as public health problems, multidisciplinary working groups are formed, as in the case of the ROP, to issue these guidelines.

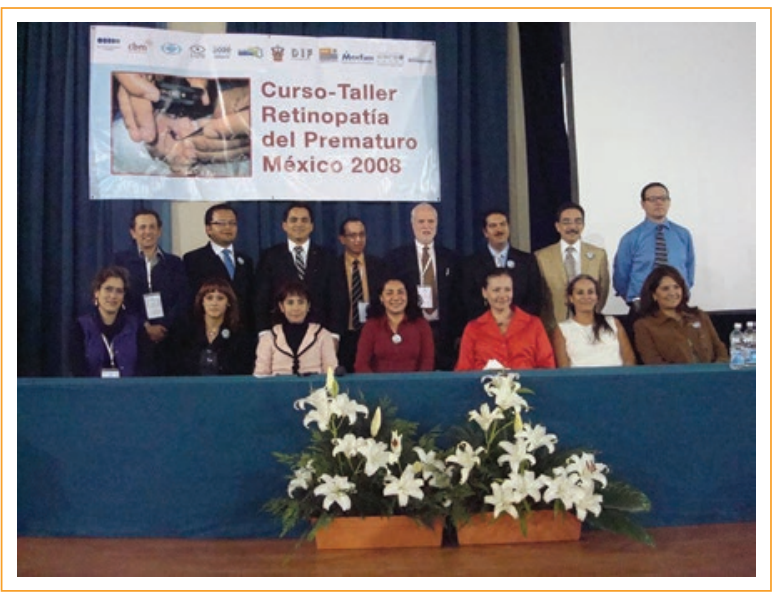

Figure 1. First ROP workshop in the city of Guadalajara, 2008.

On 2008 a workshop was held in the city of Guadalajara (Fig. 1) as well as a nationwide survey about ROP detection and treatment programs with the participation of 10 states of the Mexican Republic, and a total of 122 public and private neonatal units. The following results were obtained: from 122 neonatal units, only 26 of them performed some type of ROP detection and/or treatment, that is, only $21 \%$; the type of treatment used for severe cases of ROP was cryotherapy in $33 \%$ and laser in $67 \%$, and only two centers performed intraocular surgery for stages IV or V of the disease. Favorable results were obtained, regardless of the type of treatment used, in $82 \%$ of cases.

During 2011 and due to the relevance of ROP, the Ministry of Health, through the National Center for Gender Equity and Reproductive Health, incorporated the diagnosis and treatment of ROP in the modifications that were carried out in the Official Mexican Standard 034 for the Prevention and Control of Birth Defects, called NOM-034, with the corresponding amendments. In 2012 it was presented to the bicameral legislature for discussion and approval, which at the time represented a radical change in the management of ROP in Mexico, since afterwards, the comprehensive management of ROP in the medical field, both public and private, became mandatory, with the corresponding medical-legal implications and for the benefit of Mexican premature children.

The ROP Mexico Group conducted a new survey in July 2011. Information was obtained from 14 Mexican states, with a total of 79 neonatal public units. Forty-two units $(53 \%)$ were performing ROP detection programs and 35 units (44\%) gave ROP treatment. The type of treatment was laser in $20 \%$ of the units, combined laserplus an antiangiogenic (ranibizumab and/or 


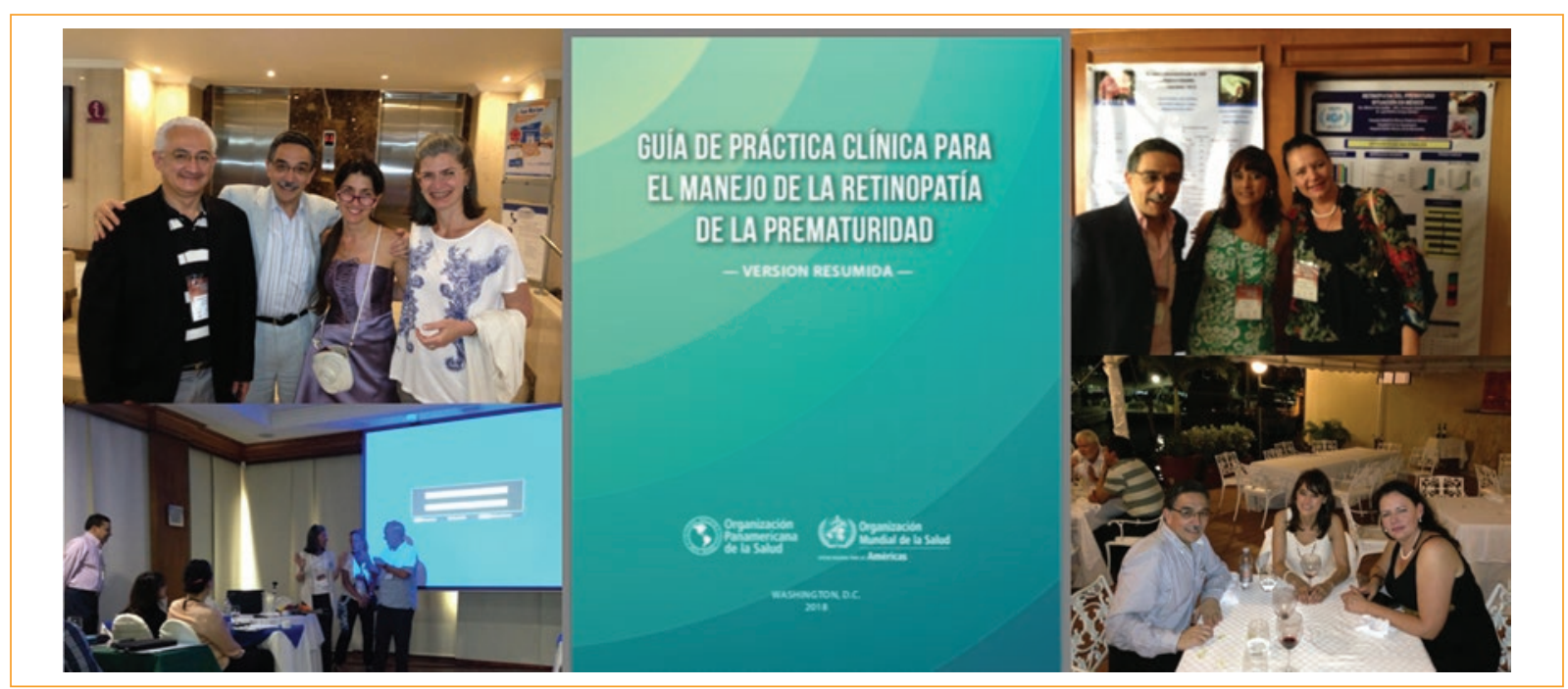

Figure 2. Participation of the ROP Mexico group in the clinical practice guidelines for the management of retinopathy of prematurity.

bevacizumab) in $60 \%$ and antiangiogenics as a single treatment in $20 \%$. This shows the increase in ROP programs in our country, and the change that has been made in a few years in ROP management, which implies medical, legal and ethical considerations, to name a few, and the imperative need for research on this topic.

On January 25, 2013, in the Official Gazette of the Federation, a decree of the General Health Law was published, which amended article 61, indicating the mandatory examination of the retina of all newborns four weeks after birth for the early detection of malformations that can cause blindness, as well as treatment in case of need. In September 2013, in the city of Cartagena de Indias, Colombia, the ophthalmologists and neonatologists of Latin American countries were summoned to prepare the guidelines for the detection and management of premature newborns with ROP. There were 3 days of intense work, which came to fruition with the subsequent publication of the guidelines (Figs. 2 and 3).

On June 3, 2014, at the request of the WHO and by presidential decree, the National Council for the Prevention and Treatment of Visual Diseases was created, whose objective was the prevention and elimination of blindness and avoidable visual disability, headed by Dr. Mercedes Juan, the Secretary of Health at the time. Ten strategies were proposed, from which number 6 was ROP screening and treatment.

The National Commissioner of Popular Insurance, Dr. Gabriel O'Shea Cuevas, Dr. Víctor Manuel Villagrán Muñoz, Deputy Director General of the $21^{\text {st }}$ Century Medical Insurance, Dr. Luz Consuelo Zepeda Romero, retinologist of the Hospital Civil de Guadalajara, and
Dr. Luis Porfirio Orozco Gómez, retinologist of the ROP Mexico Group, were summoned to organize this strategy and create the National Plan, so that at least one accredited hospital in each state of the Ministry of Health where children are born was equipped with equipment and supplies necessary for the detection and treatment of ROP, since on January 25, 2013, the Article 61 of the General Health Law had been modified, making mandatory the examination of the retina of all newborns by the fourth week of life, as well as the examination of:

- Visual function (only by the physician) within the first 28 days of life

- The examination of visual function (only by the physician) from 6 to 8 months of life

- Measuring visual acuity between 4 and 6 years old Multiple meetings were held at the Ministry of Health, which were uninterrupted despite the fact that Dr. Juan was replaced by Dr. José Narro Robles and Dr. Gabriel O'Shea was replaced by Mtro. Antonio Chemor Ruiz (Fig. 4).

The $21^{\text {st }}$ Century Medical Insurance Program, in coordination with the National Institute of Perinatology, has designed a strategy called «Integral Vital Support of the Neonate" (AVIN), which includes the use of non-invasive ventilation and the rational application of regulated oxygen to the premature newborn. This strategy includes the implementation of a training program for health personnel (pediatricians, neonatologists, nurses) responsible for neonatal care in the prevention of ROP. As part of the AVIN strategy, the provision of systems for the application of continuous positive 


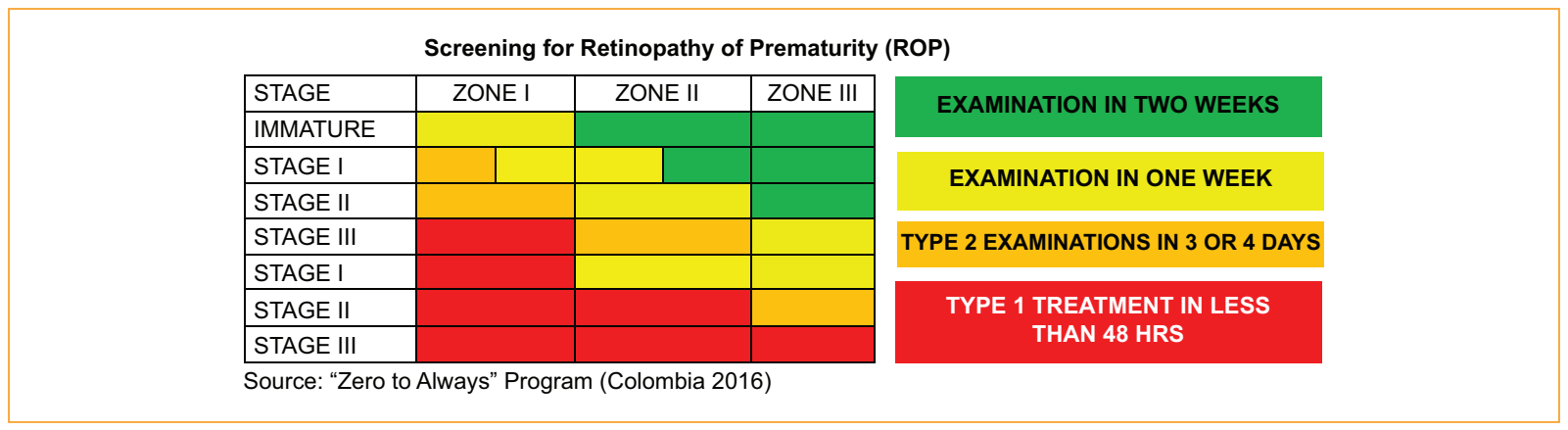

Figure 3. The ROP Mexico group adopted the "Zero to Always" program algorithm that Colombia created in 2016.

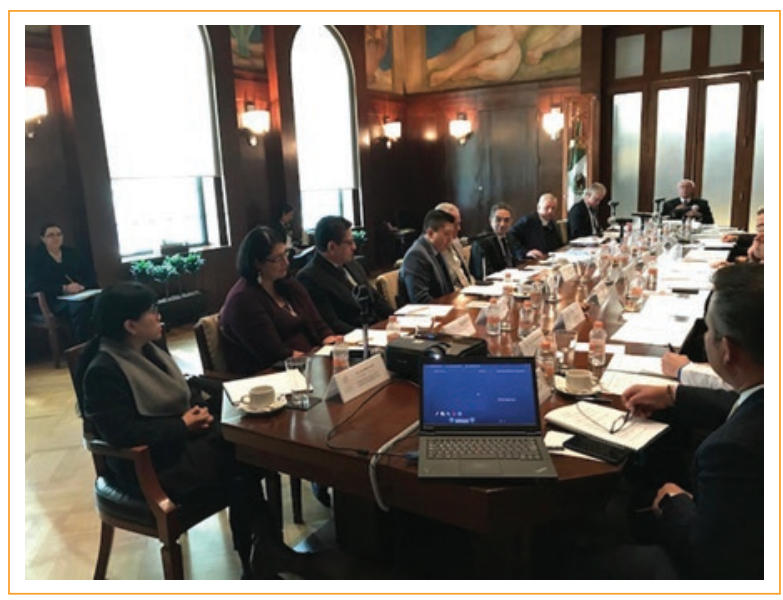

Figure 4. Meeting of the National Council for the Prevention and Treatment of Visual Diseases.

airway pressure with oxygen blenders and humidifiers has been carried out.

With all these actions, it is expected to achieve:

- The creation of a National Multidisciplinary Network of nurses, neonatologists and ophthalmologists concerned with the correct management of premature children

- The timely examination of premature newborns.

- A decrease in the currently registered annual prevalence rate of 500 blind children due to retino pathy

- To present the medical advances achieved in Mexico and the possible collaboration of all instances for the well-being of premature newborns.

All this needed the establishment of regional interdisciplinary treatment centers for patients with ROP, a follow-up program, as well as the evaluation of the impact that will demonstrate the effectiveness of the strategy that will ultimately contribute to the reduction of visual impairment.
The $21^{\text {st }}$ Century Medical Insurance Program is funding the creation of 36 regional interdisciplinary treatment centers (one for each state of Mexico) for patients with ROP, that will be operated by the state health services with the objective of contributing to the reduction of visual impairment. In September 2017, by decision of the Ministry of Health, the first phase (Table 1) of equipment was delivered to 18 states of the country that received a Ret-Cam and a solid-state laser.

It also started the training of neonatologists, pediatricians and nurses in the proper use of non-invasive ventilation and the rational application of regulated oxygen to premature infants in the Maternal hospitals of Celaya and the State of Mexico, as well as the hiring of ophthalmologists trained in ROP detection, which, by payment per event, will screen and treat patients with ROP in these centers.

September 17, 2018 was a very important day, since it marked the completion of equipment delivery to the 33 centers for the detection and management of patients with ROP. For the ceremony, the splendid hall of the University de Guadalajara was chosen, where the fantastic murals of José Clemente Orozco witnessed such an important event that represented the delivery of the second phase of equipment (indirect binocular ophthalmoscopes with magnifying lens, scleral depressor, blepharostat, pulse oximeter and solid-state laser) (Table 2) to the remaining hospitals of the Ministry of Health that have the infrastructure to admit and treat premature babies.

Dr. Luz Consuelo Zepeda was the representative of the ophthalmologists of the country, as the Hospital Civil de Guadalajara pioneered the modification of state laws to include the review of premature newborns.

A video was presented explaining the history of ROP and the modification of Jalisco's law that finally helped 
Table 1. National plan for retinopathy of prematurity (ROP), first phase

\begin{tabular}{|c|c|c|c|c|}
\hline No & Entity & Hospital (municipality) & Ophthalmologist & Medical equipmen \\
\hline 1 & Aguascalientes & $\begin{array}{l}\text { Hospital de la Mujer } \\
\text { (Cd. Satellite Morelos) }\end{array}$ & Subrogation & Laser \\
\hline 2 & Baja California & Hospital Materno Infantil (Mexicali) & Dr. Natalia I. Matti Amador & Ret-Cam/Laser \\
\hline 3 & Baja California Sur & $\begin{array}{l}\text { Hospital General con Especialidades } \\
\text { Juan María de Salvatierra (La Paz) }\end{array}$ & Subrogation & Laser/Oftalmos Ind. \\
\hline 4 & Campeche & $\begin{array}{l}\text { HG Specialties Dr. Juan Buenfil } \\
0 \text { (Campeche) }\end{array}$ & Dr. María Mayorga Castellanos & Ret-Cam/Laser \\
\hline 5 & Mexico City & Hospital Infantil de México (CDMX) & Dr. Norma Citlalli Lara Molina & Ret-Cam/Laser \\
\hline 6 & Durango & Hospital General de Durango (Durango) & Dr. Tania B. Alarcón Henao & Ret-Cam/Laser \\
\hline 7 & Guanajuato & Hospital Regional de León (León) & Dr. Olivo Gómez Vargas & Ret-Cam/Laser \\
\hline 8 & Hidalgo & Hospital General Pachuca (Pachuca) & Dr. Irma Adriana González S. & Ret-Cam/Laser \\
\hline 9 & Jalisco & $\begin{array}{l}\text { Hospital Civil de } \\
\text { Guadalajara (Guadalajara) }\end{array}$ & Dr. Consuelo Zepeda Romero & Ret-Cam/Laser \\
\hline 10 & Mexico & $\begin{array}{l}\text { Hospital Materno Perinatal Monica } \\
\text { Pretelini (Toluca) }\end{array}$ & Dr. Hugo Tapia & Ret-Cam/Laser \\
\hline 11 & Nuevo León & $\begin{array}{l}\text { Hospital Regional Materno Infantil } \\
\text { (Guadalupe) }\end{array}$ & Dr. Andrea Rangel Padilla & Ret-Cam/Laser \\
\hline 12 & Puebla & Hospital de la Mujer (Puebla) & Dr. Luis Alberto Ramírez P. & Ret-Cam/Laser \\
\hline 13 & San Luis Potosi & $\begin{array}{l}\text { Hospital Central Dr. Ignacio Morones } \\
\text { Prieto SLP }\end{array}$ & Dr. Martha Griselda Rangel & Ret-Cam/Laser \\
\hline 14 & Sinaloa & Hospital de la Mujer (Culiacan) & Dr. Ruth Acuña Maldonado & Ret-Cam/Laser \\
\hline 15 & Sonora & $\begin{array}{l}\text { Hospital Infantil Dra. Luisa María Godoy } \\
\text { Olvera (Hermosillo) }\end{array}$ & Dr. Nestor Hugo Garrido & Ret-Cam/Laser \\
\hline 16 & Tamaulipas & $\begin{array}{l}\text { Hospital General Materno Infantil } \\
\text { (Reynosa) }\end{array}$ & Dr. Víctor González & Ret-Cam/Laser \\
\hline 17 & Yucatan & $\begin{array}{l}\text { Hospital General } \\
\text { Agustín } \mathrm{O} \times \text { Horan (Merida) }\end{array}$ & Dr. Alejandro Solís Castillo & Ret-Cam/Laser \\
\hline 18 & Zacatecas & Hospital de la Mujer (Guadalupe) & Dr. Adriana Ramírez López & Ret-Cam/Laser \\
\hline
\end{tabular}

All units were equipped with 3 Flynn scleral depressors, three Barraquer blepharostats for premature babies, aspherical magnifying lens, three pediatric neonatal pulse oximeters and an indirect binocular ophthalmoscope.

in 2013 to modify the article 61 of the General Health Law, where the examination of the retina was made mandatory at the fourth week life for every newborn.

As guests of honor for this event, were Dr. Francisco Martínez Castro, former president of the Pan American Ophthalmology Association, Dr. Marco Antonio de la Fuente Torres, president of the Sociedad Mexicana de Oftalmología, which was represented by Jaime Navarro, and myself, president of the Pan American Society of Retinopathy of Prematurity (Fig. 5).

The symbolic delivery of the equipment to Dr. Consuelo Zepeda by the Secretary of Health, Dr. José Narro Robles, caused a standing ovation from the audience. Directors of hospitals and neonatal units throughout the country, as well as university authorities, stood up as a sign of solidarity for the successful completion of this program (Fig. 6).

Another achievement on this topic was made in 2017, since we had the privilege of being able to hold the IV World Congress of Retinopathy of Prematurity in the city of Cancun in September, with the participation of 42 countries from 5 continents, with 410 participants and 90 international professors. Mexico was placed among one of the Latin American countries that already has a ROP program.

One of the things that caught the attention of the participants was the usefulness of the smartphone to document and screen the disease. The smartphone helps to maintain a chat where more than 160 ophthalmologists are connected for immediate discussion and 
Rev Mex Oftalmol (Eng). 2019;93

Table 2. National plan for retinopathy of prematurity (ROP), second phase

\begin{tabular}{|c|c|c|c|c|}
\hline No & Entity & Hospital (municipality) & Ophthalmologist & Medical equipment \\
\hline 1 & Coahuila & Saltillo University Hospital & Subrogation & Laser/Oftalmos Ind. \\
\hline 2 & Colima & Regional University Hospital & Subrogation & Laser/Oftalmos Ind. \\
\hline 3 & Chiapas & Hospital Regional Dr. Rafael Pascasio Gamboa (Tuxtla) & Subrogation & Laser/Oftalmos Ind. \\
\hline 4 & Chihuahua & Hospital de la Mujer (Cd. Juarez) & Subrogation & Laser/Oftalmos Ind. \\
\hline 5 & Mexico City & Hospital Materno Infantil (Inguaran) & Subrogation & Laser/Oftalmos Ind. \\
\hline 6 & Chilpancingo & Hospital de la Madre y del Niño (Chilpancingo) & Subrogation & Laser/Oftalmos Ind. \\
\hline 7 & Jalisco & Hospital General de Occidente (Guadalajara) & Subrogation & Laser/Oftalmos Ind. \\
\hline 8 & Michoacan & Hospital de la Mujer (Morelia) & Subrogation & Laser/Oftalmos Ind. \\
\hline 9 & Morelos & Hospital del Niño Morelense & Subrogation & Laser/Oftalmos Ind. \\
\hline 10 & Nayarit & Hospital civil Dr. Antonio González Guevara & Subrogation & Laser/Oftalmos Ind. \\
\hline 11 & Oаxaca & $\begin{array}{l}\text { Hospital de Especialidades de la Niñez Oaxaqueña } \\
\text { (San Bartolo Coyotepec) }\end{array}$ & Subrogation & Ret-Cam/Laser \\
\hline 12 & Queretaro & $\begin{array}{l}\text { Hospital de Especialidades del Niño y la Mujer Felipe Núñez } \\
\text { Lara }\end{array}$ & Subrogation & Laser/Oftalmos Ind. \\
\hline 13 & Quintana Roo & Hospital Materno Infantil (Morelos) & Subrogation & Laser/Oftalmos Ind. \\
\hline 14 & Tabasco & Hospital Regional de Alta Especialidad Dr. Rodolfo Nieto Padrón & Subrogation & Laser/Oftalmos Ind. \\
\hline 15 & Tlaxcala & Hospital Infantil de Tlaxcala & Subrogation & Laser/Oftalmos Ind. \\
\hline 16 & Veracruz & Río Blanco Regional Hospital & Subrogation & Ret-Cam/Laser \\
\hline
\end{tabular}

All units were equipped with 3 Flynn scleral depressors, three Barraquer blepharostats for premature babies, aspherical magnifying lens, three pediatric neonatal pulse oximeters and an indirect binocular ophthalmoscope.

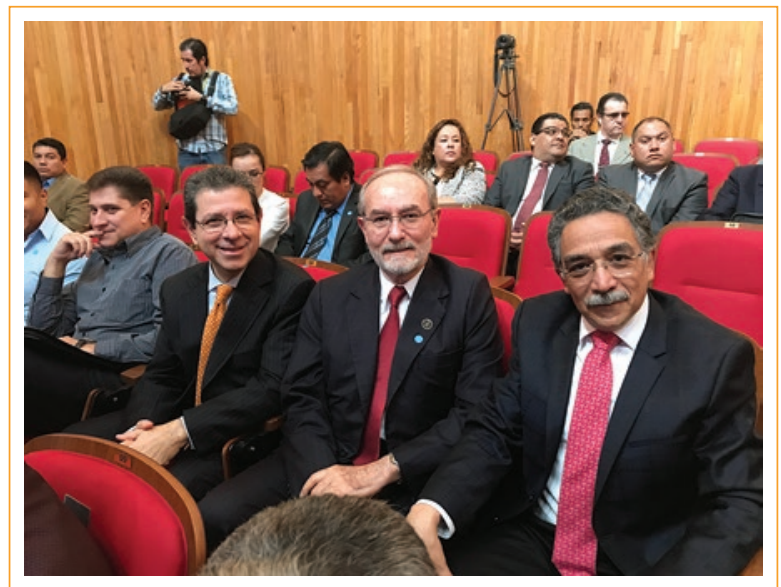

Figure 5. In the picture from left to right: Dr. Javier Navarro, representative of the President of the SMO 2018; Dr. Francisco Martínez Castro, President of the IAPB; and Dr. Luis Porfirio Orozco, President of SP-ROP.

decision-making for the treatment of the disease. During the congress, a practical course was given on the usefulness of such a valuable tool to be able to share images worldwide. In the area of neonatology, two topics

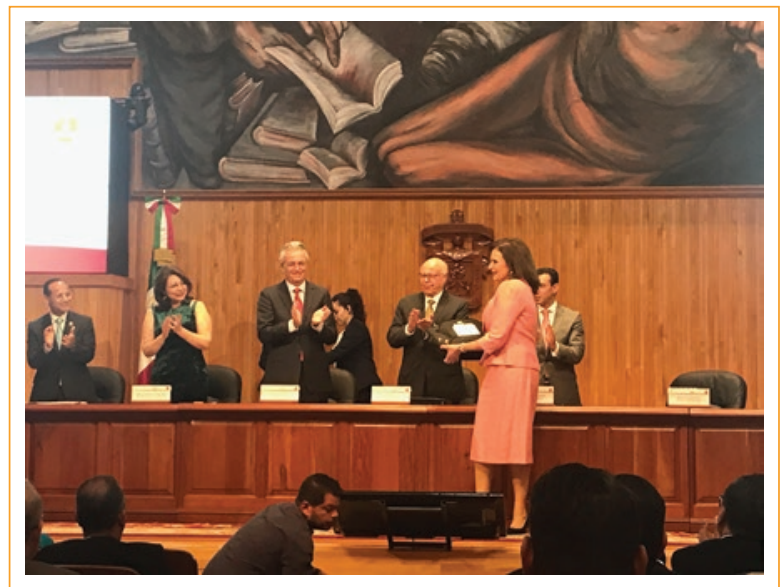

Figure 6. Dr. Consuelo Zepeda from the state of Jalisco receives equipment from the Secretary of health, Dr. José Narro Robles.

stood out: prevention and treatment of ROP and perinatal strategies in its prevention, as well as the statistics of the nursing staff available to attend this population (3.9 per 1,000 inhabitants). Finally, during the closing ceremony of the Congress, The Bernadotte Foundation 


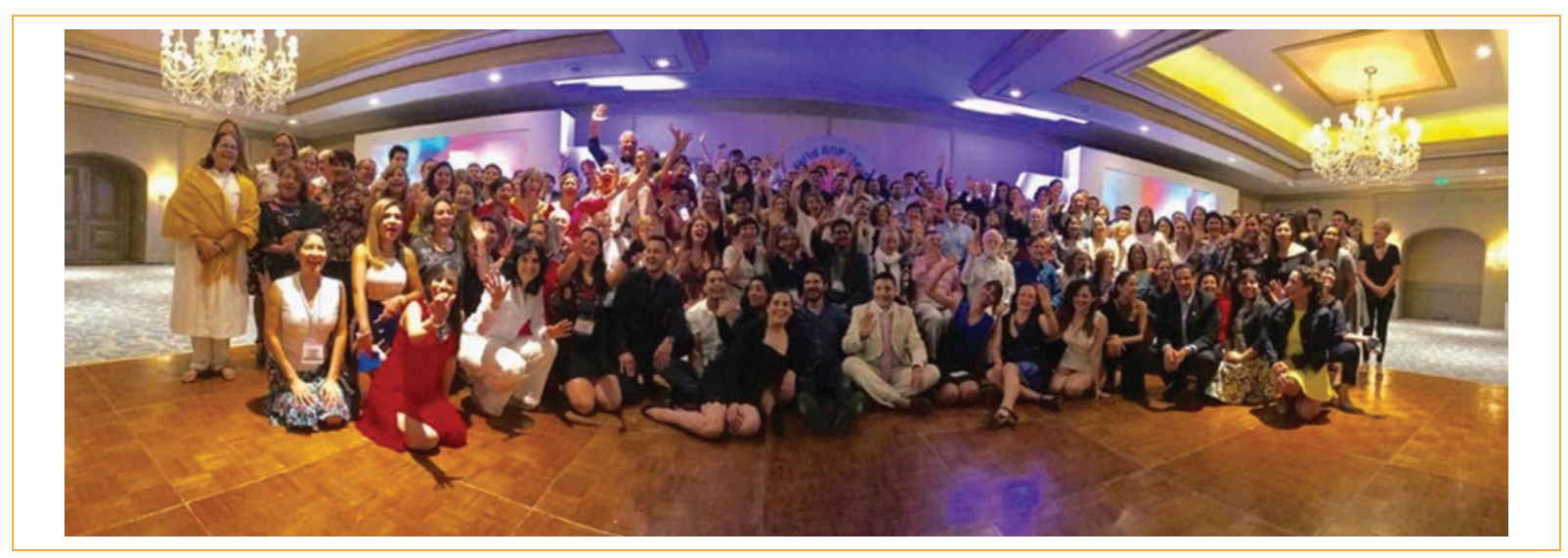

Figure 7. IV World Congress of Retinopathy of Prematurity in the city of Cancun, 2017.

for Children's Eye Care, Inc. awarded acknowledgements and 13 scholarships (Fig. 7).

With all of the above, it is clear that a group of specialists can take the lead in changing national policies for the control and treatment of pathologies that can be prevented if we work in a coordinated manner. The National Plan for the Detection and Management of Retinopathy of Prematurity is a reality today. Let us continue working together to reduce the number of blind patients due to this pathology and show that this program works.

\section{Ethical disclosures}

Protection of human and animal subjects. The authors declare that no experiments were performed on humans or animals for this study.

Confidentiality of data. The authors declare that they have followed the protocols of their work center on the publication of patient data.

Right to privacy and informed consent. The authors declare that no patient data appear in this article. 